\title{
WATER PROFILE DETERMINATION IN A RUNNING PEMFC BY SMALL-ANGLE NEUTRON SCATTERING.
}

\author{
G. Gebel ${ }^{1}$, O. Diat ${ }^{1}$, S. Escribano ${ }^{2}$, R. Mosdale ${ }^{2}$ \\ ${ }^{1}$ DRFMC/SI3M/Groupe Polymères Conducteurs Ioniques \\ ${ }^{2}$ DTEN/SCSE/Laboratoire Hydrogène et Piles à Combustible \\ CEA Grenoble, 17, rue des martyrs - 38054 GRENOBLE cedex 9, France
}

A fuel cell is an electrochemical system producing a The determination of the water concentration profile DC current from two half chemical reactions: an $\mathrm{H}_{2}$ across the Nafion ${ }^{1}$ membrane and under fuel cell (the fuel) oxydation at the anode and the reduction of operation can be achieved using small-angle neutron the $\mathrm{O}_{2}$ at the cathode as indicated in figure 1a. Proton scattering (SANS) technique. Indeed, both the shape exchange membrane fuel cell (PEMFC) is a cell and the level of scattered intensities of Nafion spectra using a proton conducting polymeric membrane as a are very sensitive to the water content. Moreover, it is solid electrolyte separating both electrodes (and so possible to use a specially designed fuel cell which is both gases) and allowing the proton conduction almost transparent to neutrons and allows mainly the between the anode and the cathode. These observation of the membrane contribution to the membranes require a minimum of water content to SANS spectra. In a previous study, we have exhibit a sufficient conductivity and this water has to demonstrated the feasibility of such experiments but be controlled whatever the temperature and current with some poor fuel cell performances due to i) density conditions during the cell operation. Then, electrodes which were not appropriate (chemically the management of the water around the cell and deposited platinum) ii) a cell design which did not more especially between both electrodes is a major allow an optimized gas flow on the membrane and challenge for PEMFC applications. When the cell is iii) a control of the cell temperature which were nonoperating, water is produced at the cathode. existent. In the present study, a new bench and a new Therefore, under stationary conditions and depending cell were designed (see Fig. 2) to operate at $80^{\circ} \mathrm{C}$ and on the current density, an excess of water under pressure, to control the gas flow, and to accumulates at the cathode and has to be removed. measure the gas outlet humidities.

Nevertheless, it exists always a water concentration profile across the membrane, which is partially counterbalanced by water back-diffusion and reinforced by water electro-osmosis (see Fig. 1b). This concentration profile can also be reduced using humidified inlet gases especially at the anode.

Several attempts to experimentally determine these profiles during fuel cell operation have been published. However the experimental constraints [14] ${ }^{1-4}$ lead to operate in conditions, which were not representative of the actual fuel cell operation.

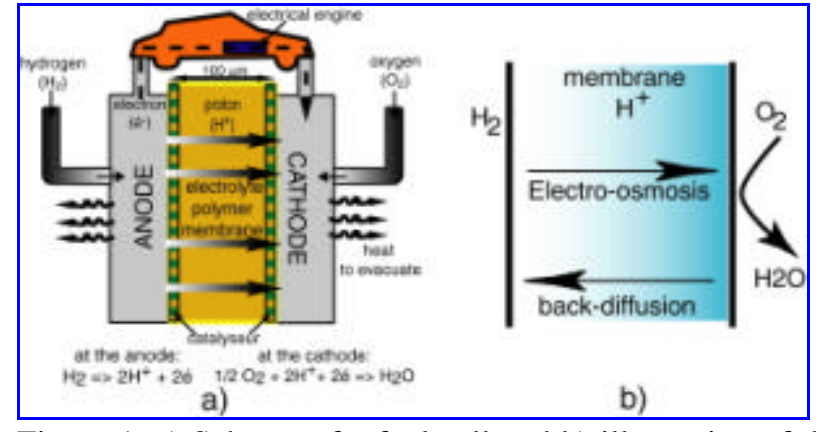

Figure 1. a) Scheme of a fuel cell and b) illustration of the water management in an operating fuel cells

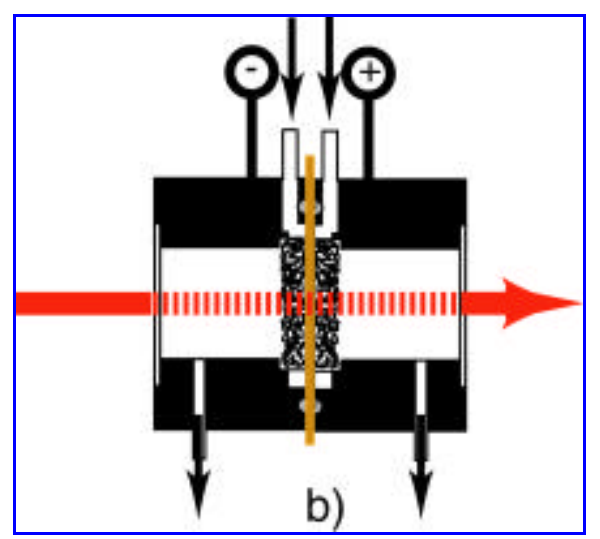

Figure 2. Porous gas distributors and current collectors are either in an titanium/zirconium alloy (48/52) which was grated and sintered or in highly porous steel $(90 \%$ porosity). Quartz windows were to insure each compartment to be airtight and the transparency to neutrons. The temperature was measured through a thermocouple and adjusted through a temperature controller. Two different types of electrodes were used either a spray $(\mathrm{Sm})$ or a hot pressed Etek $^{(B)}$ electrode (Etn) on membrane. In the case of Etn electrodes the diffusion layer has been torn away in order to deposit the active layer on the membrane and to avoid the strong scattering of the carbon tissue.

\footnotetext{
${ }^{1}$ Nafion $^{\circledR}$ is a perfluorinated membranes purchased from du Pont de Nemours Company
} 
The experiments (see an example in Fig. 3a) were to $80^{\circ} \mathrm{C}$. The current density was then increased by performed starting from a nearly dry membrane and step after at least the stabilization of the fuel cell varying both the current density and the gas performance and of the SANS spectra (typical steps stoechiometry in order to determine the kinetics of of current were between 1 and 2 hours). The analysis swelling in addition to the water concentration in term of water concentration profiles is presented in profiles. Following the different scattering profiles figure $3 b$.

shown in Fig. 3, the membrane was first dried by a

flow of dry gases and increasing the temperature up
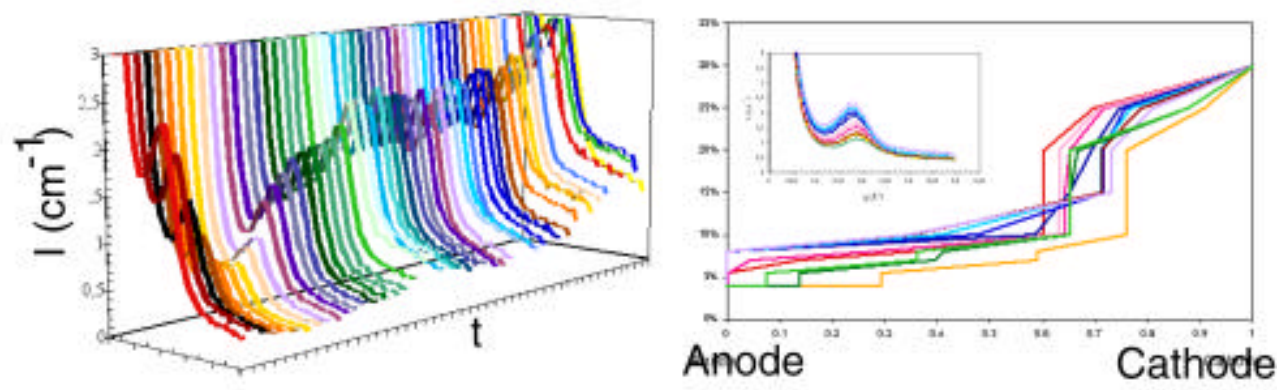

Figure 3. Series of SANS spectra (left) obtained from a Nafion 115 membrane using highly porous gas distributors. The membrane is first dried and then the current density is increased from 0 to $1 \mathrm{~A} / \mathrm{cm}^{2}$. Example of a series of experimental data extracted from left. Each curve were fitted (inset) and the corresponding profiles (\% of water into the membrane as a function of thickness) are presented (right) for different current densities.

It was shown that it is possible to determine the overall water content of the membrane under operation and to follow its evolution depending on the operating conditions fitting the data using a linear combination of referenced spectra (obtained from membranes at given humidity and placed in similar support and temperature conditions).

The performances and the stability of the fuel cell (polarization curves not shown here) were very good which suggests that the membrane has not to be completely water swollen as it is usually believed. Others experiments indicate that the fuel cell can run with a nearly dry membrane but the operating parameters such as the gas flow, the humidification or the temperature becomes crucial.

\section{Acknowlegdments :}

The authors would like to thank the Laboratoire Léon Brillouin and J. Teixeira as local contact for their help in the realization of neutron experiments. This work has been granted by the Direction Scientifique de la CEA-DRT (Action incitative $\mathrm{EDiP}-\mathrm{ACAV} \mathrm{n}{ }^{\circ}$ 7).

\section{References}

[1] Watanabe, M.; Igarashi, H.; Uchida, H.; Hirasawa, F. Journal of Electroanalytical Chemistry, 399 (1995) 239

[2] Mosdale, R.; Gebel, G.; Pineri, M. Journal of Membrane Science, 118 (1996) 269.

[3] Bellows, R. J.; Lin, M. Y.; Arif, M.; Thompson, A. K.; Jacobson, D. Journal of The Electrochemical Society, 146 (1999) 1099.

[4] Büchi, F. N.; Scherer, G. G. Journal of The Electrochemical Society, 148, (2001) 183 